\title{
Computer-Supported Career Development in the Future of Work
}

\author{
Julie Hui \\ University of Michigan \\ Ann Arbor, IL 48109 \\ juliehui@umich.edu \\ Elizabeth M. Gerber \\ Northwestern University \\ Evanston, IL 60208 \\ egerber@northwestern.edu \\ Lynn Dombrowski \\ IUPUI \\ Indianapolis, IN 46202 \\ Isdombro@iupui.edu \\ Mary L. Gray \\ Microsoft Research Labs \\ Cambridge, MA 02142 \\ mlg@microsoft.com \\ Adam Marcus \\ B12 \\ New York, NY 10003 \\ marcua@marcua.net \\ Niloufar Salehi \\ UC Berkeley \\ Berkeley, CA 94720 \\ salehi@ischool.berkeley.edu
}

\section{Abstract}

As people increasingly work different jobs, the responsibility of building long-term career satisfaction and stability increasingly falls more on the workers rather than individual employers. With technologies playing a central role in how people choose and access employment opportunities, it is necessary to understand how online technologies are shaping career development.

Permission to make digital or hard copies of part or all of this work for personal or classroom use is granted without fee provided that copies are not made or distributed for profit or commercial advantage and that copies bear this notice and the full citation on the first page. Copyrights for third-party components of this work must be honored. For all other uses, contact the Owner/Author.

CSCW '18 Companion, November 3-7, 2018, Jersey City, NJ, USA (c) 2018 Copyright is held by the owner/author(s).

ACM ISBN 978-1-4503-6018-0/18/11.

https://doi.org/10.1145/3272973.3274545
We bring together leading human-computer interaction researchers, industry members, and community organizers, who have worked with systems and people across the socio-economic spectrum during the career development process. We will discuss research on the role of online technologies in career development, including but not limited to topics in crowd work, social media sites, and freelance work sites.

\section{Author Keywords}

Career; Career development; Future of work; crowd work; freelance work; MOOCS; Online technologies.

\section{Introduction}

Internet technologies have long been praised for offering unprecedented support for career development-the ability to decide and advance in job paths that improve one's career standing over time [6]. This includes being able to learn key skills needed in the workplace (e.g. with MOOCS), develop productive relationships with peers and mentors (e.g. through professional networking platforms), and access meaningful income-earning opportunities (e.g. on gig work, crowd work platforms). And yet, we still see a widening divide in who is able to advance their career standing in meaningful ways using these technologies. For instance, marginalized groups and blue collar workers are often less likely to benefit from widely used employment platforms because they have less control over their day-to-day work data [2] and lack the seed connections needed to leverage relationships online $[1,4]$. Similarly, crowd work platforms often limit worker agency when deciding the work that they do, their pay, and collective organizing $[5,7]$. To develop platforms that truly support career develop- 
ment of workers of all types, we must engage in complicated discussions around the role of technology, and how it can facilitate rather than exacerbate existing challenges in career development.

Themes. The panel discussion will be framed around the following five themes:

- Under what conditions do online technologies impact people's career mobility and satisfaction?

- How have design features of online platforms (e.g. algorithms, user affordances) created more or less equitable opportunities for career development?

- How can online technologies facilitate existing career development support structures, like managers and career centers?

- How have online technologies changed how people learn new skills for their jobs?

- What are the differences between peer-based career development and other sites of institutional/organizational support?

\section{Panel Format}

We will attract researchers and practitioners studying and building systems that influence career development. This includes, and not limited to, people who study or design aspects of crowd work, social networking sites, career development, and job seeking.

Before the panel. We will invite questions/comments from CSCW participants through Twitter one-month prior to the conference to inform the direction of the panel and to allow participants to build on one another's ideas.

During the panel. The moderator and each panelist will provide a brief overview of their work and perspective as it relates to career development research and practice. The moderator will then ask a series of questions framed by the main topic areas and questions posed on Twitter. The remaining time will address the questions proposed by the audience. The conversation will be captured in real time by two student volunteers. One will capture the dialogue to be placed on a blog, and the other will be tweeting to the CSCW community and beyond using hashtags \#CSCW2018 and \#TheFutureOfWork.

After the panel. Taking inspiration from crowdresearch.org, a blog that invites crowdsourcing researchers to write posts on their research, we will summarize the panel conversation and foster additional discussion around computer-supported career development research on an online blog.

\section{Moderator and Panelists}

Julie Hui is an Assistant Professor/Presidential Postdoc in University of Michigan's School of Information. She is currently working with small business owners and community organizations in Detroit to develop side-income opportunities and more accessible pathways to employment. Her larger goal is to understand how online and offline communities can be designed to better facilitate new forms of apprenticeship between experts and novices.

Position Statement: As online technologies become more central to how people find and participate in work in the $21^{\text {st }}$ century, it becomes imperative to understand how these platforms support overall career satisfaction and control over one's future. Online platforms should not just be designed to support easy access to income in the short-term, but also support long-term relationship development and skill development.

Elizabeth M. Gerber is the Charles Deering McCormick Professor of Teaching Excellence and Associate Professor of Design at Northwestern University where she directs the Design Research Cluster and serves as core faculty for the Technology and Social Behavior Program. Elizabeth's research looks at how technology is designed to support collaboration across informal and formal organizational structures, including crowdsourcing and crowdfunding work platforms. She has published research in design, computer science, management science, and learning science journals and 
sits on the editorial board of ACM's Transactions on Social Computing. Elizabeth also writes for and has been covered by popular press venues including The Wall Street Journal, National Public Radio, ABC, Harvard Business Review, Forbes, and Fast Company. Elizabeth founded and serves as the faculty director of Design for America, the recipient of the Cooper Hewitt Design Institutional Excellence Award in 2018.

Position statement: As long term employment disappears, the relationship between the manager and employee becomes increasingly important and complex. Good managers support career development to increase productivity and profit, and to reduce turnover. We must build socio-technical systems to support managers in facilitating strategic planning with employees who have diverse work schedules and overall needs.

Lynn Dombrowski is an Assistant Professor of Human-Centered Computing at Indiana University, Purdue University-Indianapolis. Her work focuses on examining and designing human-centered technologies for intervening in large systemic social issues, like social and economic inequalities and how to design for social justice.

Position Statement: The future of work will likely be impacted by novel computing technologies such as automation, Internet of Things, worker-focused data surveillance, etc. Historically, such work-focused computing innovations have not been inherently progressive or liberating as they are often designed for management of work/ers but not necessarily for workers themselves. Thus, this poses compelling design opportunities and challenges for CSCW to rethink cultural and economic assumptions underlying workplace computing technologies, to defamiliarize work, and to reimagine the future of work.

Mary L. Gray is a Senior Researcher at Microsoft Research and Fellow at Harvard University's Berkman Klein Center for Internet and Society. She maintains a faculty position in the School of Informatics, Compu- ting, and Engineering at Indiana University. Mary's research looks at how technology access, material conditions, and everyday uses of media transform people's lives. She is the author of In Your Face: Stories from the Lives of Queer Youth, and Out in the Country:

Youth, Media, and Queer Visibility in Rural America, and is co-editor of Queering the Countryside: New Directions in Rural Queer Studies a Choice Academic Title for 2016. Mary's forthcoming book Ghost Work (Houghton Mifflin Harcourt 2019), in collaboration with Siddharth Suri, explores the impact of automation on the future of work through workers' present-day experiences of ondemand economies. Mary currently sits on several boards addressing questions about the automation and the future of work and social responsibility in tech, including the Executive Board of Public Responsibility in Medicine and Research (PRIM\&R) and Stanford University's "One-Hundred-Year Study on Artificial Intelligence" (AI100) Standing Committee.

Position Statement: Scientists and engineers will continue the quest to build AIs capable of human level thought in an effort to replace humans and fully automate work. Debating whether or not this is ultimately achievable distracts us from addressing the immediate needs of today's on-demand workforce. In doing so, people doing "ghost work" will be necessary contributors to current AI systems that cannot figure things out on their own. Human labor will be necessary, at least for the foreseeable future.

Niloufar Salehi is an Assistant Professor at the School of Information at UC Berkeley. Her research interests are in social computing, technologically mediated collective action, digital labor, and computer supported cooperative work. Her work has been published and received awards in premier venues in human-computer interaction including $\mathrm{CHI}$ and $\mathrm{CSCW}$.

Position Statement: I have studied challenges to worker collective action by engaging with Amazon Mechanical Turk workers (Turkers) through over a year of ethnographic fieldwork. Together with Turkers we cre- 
ated Dynamo, a platform to support the Mechanical Turk community in forming publics and mobilizing around issues. Dynamo shows how structured human labor ("human infrastructure") can help move efforts forward when they stall. If one views Mechanical Turk, requesters, $\mathrm{HCI}$, and mainstream media portrayals of AMT collectively as a dominant public, then Dynamo, Turkopticon, and worker forums would represent counter publics formed to articulate alternatives to wider public discourses. Counterpublics require shields and temporary suspension of mainstream norms of discourse to form. How might social technology help create the conditions for such discourse and action?

Adam Marcus is a co-founder and CTO of B12, a startup focused on building a brighter future of creative and analytical work. Previously, Adam was Director of Data at Locu, a startup that was acquired by GoDaddy. He has written on crowdsourcing and data science, including co-authoring a book, Crowdsourced Data Management: Industry and Academic Perspectives. He is a recipient of the NSF and NDSEG fellowships and has worked at ITA, Google, IBM, and FactSet. Adam holds a Ph.D. in Computer Science from MIT's CSAIL, where he researched database systems and human computation.

Position Statement: Most discussions of AI explore how it might automate work, but not enough focus on how it might elevate expertise. AI work platforms should increasingly integrate automation to eliminate rote labor, offer choice in picking new work opportunities, and establish mentorship opportunities along the way. B12's open source human-assisted AI work platform Orchestra (http://orchestra.b12.io/) integrates machines onto flash teams to reduce rote labor. Through its StaffBot functionality, experts are offered choice amongst available tasks. With hierarchical review [3], trusted experts can provide mentorship to entry-level workers, increasing work quality while affording growth opportunities. While its implementation details deserve scrutiny and iteration, Orchestra provides a working case study of how AI can elevate expertise.

\section{References}

1. Tawanna R. Dillahunt, Nishan Bose, Suleman Diwan, and Asha Chen-Phang. 2016. Designing for disadvantaged job seekers: Insights from early investigations. In Proc. of the ACM Conference on Designing Interactive Systems, 905-910.

2. Lynn Dombrowski, Adriana Alvarado Garcia, and Jessica Despard. 2017. Low-wage precarious workers' sociotechnical practices working towards addressing wage theft. In Proc. of the ACM Conference on Human Factors in Computing Systems, 45854598.

3. Daniel Haas, Jason Ansel, Lydia Gu, and Adam Marcus. 2015. Argonaut: macrotask crowdsourcing for complex data processing. Proceedings of the VLDB Endowment 8, 12: 1642-1653.

4. Julie Hui and Elizabeth M. Gerber. 2018. IntroAssist: A Tool to Support Writing Introductory Help Requests. In Proc. of the ACM Conference on Human Factors in Computing Systems.

5. Lilly C. Irani and M. Silberman. 2013. Turkopticon: Interrupting worker invisibility in amazon mechanical turk. In Proc. of the Conference on Human Factors in Computing Systems, 611-620.

6. Robert W. Lent and Steven D. Brown. 2013. Understanding and facilitating career development in the 21st century. Career development and counseling: Putting theory and research to work 2: 1-26.

7. Niloufar Salehi, Lilly C. Irani, Michael S. Bernstein, Ali Alkhatib, Eva Ogbe, Kristy Milland, and others. 2015. We are dynamo: Overcoming stalling and friction in collective action for crowd workers. In Proc. of the Conference on Human Factors in Computing Systems, 1621-1630. 